\title{
Zelfregulatie door het stellen van leerdoelen in gespreksvaardigheidsonderwijs
}

\author{
J.M.M. van de Ridder, F.J.M. Grosfeld
}

\section{Samenvatting}

Inleiding: Het huidige geneeskundeonderwijs, bijvoorbeeld probleemgestuurd onderwijs, is gebaseerd op constructivistische uitgangspunten. Dit betekent dat studenten meer dan voorheen hun leerproces zelf dienen vorm te geven. Doelen stellen is een middel om leren te sturen. De vraag is in hoeverre studenten hiertoe in staat zijn, omdat bij werkgroepbegeleiders de indruk bestaat dat studenten veelal ongericht leren. In een exploratieve studie wordt gepoogd inzicht te krijgen in de wijze waarop geneeskundestudenten hun doelen stellen. Uitgangspunt vormt het zelfregulatiemodel van Zimmerman. In een pilotstudy is nagegaan welke leerdoelen studenten zich stellen gedurende het gespreksvaardigheidsonderwijs. Onderzocht is in hoeverre deze leerdoelen in pro- en retrospectief opzicht relevant blijken.

Methode: Op basis van hun leerervaring en de resultaten van een gespreksvaardigheidstoets uit jaar 1 is aan twaalf tweedejaars geneeskundestudenten gevraagd leerdoelen te formuleren op een zelfbeoordelingsvragenlijst. Na schriftelijke feedback van de werkgroepbegeleider konden studenten hun leerdoelen aanpassen. Door twee beoordelaars zijn deze leerdoelen op onderwerp gecategoriseerd en op realiseerbaarheid beoordeeld.

Resultaten: De onderwerpen uit de 24 leerdoelen betreffen vooral de onvoldoende gescoorde items uit de toets van het jaar ervoor: (door)vragen en emoties hanteren. 22 leerdoelen bleken realiseerbaar. Feedback van de werkgroepbegeleider was gericht op het aantal impliciete leerdoelen en de eenduidigheid van de formuleringen.

Conclusie en discussie: Studenten verwerken informatie die eerder in het leerproces is verkregen op actieve wijze; ze lijken weinig problemen te hebben met het formuleren van leerdoelen en behoeven weinig bijsturing. Daarom wordt in verder onderzoek geëxploreerd hoe studenten hun leerdoelen denken te realiseren. (Ridder JMM van de, Grosfeld FJM. Zelfregulatie door het stellen van leerdoelen in gespreksvaardigheidsonderwijs. Tijdschrift voor Medisch Onderwijs 2005;24(6):250-258.)

\section{Inleiding}

In het medisch onderwijs komen studenten vroeg in aanraking met de klinische context. Probleemgestuurd onderwijs is daar een voorbeeld van. Aan de hand van een probleem proberen de studenten hun eigen weg te vinden en hun leerproces vorm te geven. Daarin zijn leerdoelen belangrijk:

"Mijn doelen voor deze communicatieserie zijn als volgt: Ten eerste wil ik proberen mijn spreektempo omlaag te brengen en de patiënt meer aan het woord te laten. Daarnaast wil ik proberen zoveel mogelijk oog te hebben voor de situatie van de patiënt en mijn advies en verloop van het consult daar ook op aan te passen.

Naast de overduidelijke redenen waarom deze vaardigheden belangrijk zijn, zijn er persoonlijke redenen waarom ik me op deze twee doelen ga toespitsen. Om te beginnen is het een bekend probleem dat [ik] de neiging heb soms te snel te praten, waardoor de patiënt soms nog informatie wil toevoegen maar dan door mij wordt 
onderbroken. Met betrekking tot de tweede doelstelling is het zo dat ik ook af en toe een bepaald doel voor ogen heb bij aanvang van het consult en dat dan ook probeer te bereiken, terwijl soms een vervolgafspraak of een andere uitkomst een beter resultaat zou bieden." (nr. 12Wm).

In het bovenstaande beantwoordt een student twee vragen: 'Wat wil ik leren?' en 'Waarom wil ik dat leren?' Stuurt deze student zijn leerproces? Zo ja, op welke manier? Zo nee, wat moet hij daarvoor dan doen? Is het formuleren van doelen een zinvol middel om leren te sturen? Dergelijke vragen spelen een belangrijke rol in een tijd die vraagt om studenten die hun leerproces zelf reguleren, vanwege de constructivistische uitgangspunten waarop onderwijs veelal is gebaseerd.* Doelen stellen is een centraal uitgangspunt van zelfregulatie. ${ }^{1}$

\section{Context: constructivistisch onderwijs}

In constructivistisch onderwijs worden studenten aangemoedigd hun eigen kennis te construeren in plaats van dit klakkeloos over te nemen van een autoriteit. Samenwerking met anderen is daarbij belangrijk, evenals een realistische onderwijscontext die overeenkomsten met een authentieke situatie vertoont. ${ }^{2}$ Constructivistisch onderwijs heeft dus gevolgen voor de rollen van docenten en studenten. ${ }^{3-4}$

Docenten hebben niet meer een vanzelfsprekende, centraal sturende rol. Ze zijn vaak facilitator van het leerproces in plaats van kennisoverdragers. Ze steunen studenten op zodanige wijze (scaffolding) dat studenten steeds meer verantwoorde- lijkheid voor hun eigen ontwikkeling en leerproces overnemen. Docenten coachen de studenten daarbij. ${ }^{5-6}$

Studenten zullen actief moeten participeren in het onderwijs om eigen kennis te kunnen construeren. Ze kunnen hun leerproces vormgeven door na te gaan: 'Wat wil ik leren?', 'Waarom wil ik dat leren?' en 'Hoe wil ik dat leren?'7 Dat vereist inzicht in het leerproces. Ze moeten zichzelf doelen kunnen stellen, deze uitvoeren, evalueren en bijstellen, kortom hun leren kunnen reguleren.

\section{Zelfregulatie}

Zimmerman beschouwt zelfregulatie als een cyclisch proces dat uit drie fasen bestaat: planning, uitvoering en zelfreflectie. ${ }^{8}$

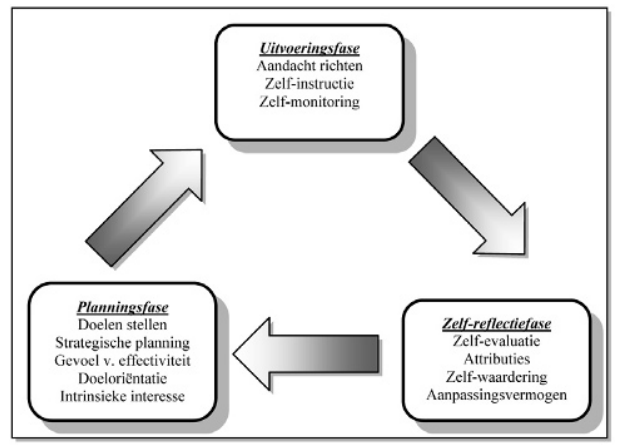

Figuur 1. Zelfregulatiemodel naar Zimmerman. ${ }^{9}$

De planningsfase heeft betrekking op de activiteiten die aan het leren vooraf gaan. In dit stadium stelt de student doelen op en denkt na over de strategie waarlangs de doelen kunnen worden bereikt. Intrinsieke motivatie en opvattingen over de zelfwerkzaamheid (self-efficacy) spelen daarbij een belangrijke rol. Daarnaast kan de

\footnotetext{
* De term 'constructivisme' wordt op veel verschillende manieren gebruikt. Deze term kan betrekking hebben op de leerpsychologische, epistemologische en didactische uitgangspunten van het onderwijs. In veel gevallen slaat de term niet op de leerpsychologische of epistemologische, maar op de didactische uitgangspunten. In dit artikel worden de didactische uitgangspunten bedoeld als geschreven wordt over constructivisme. Zie voor dit onderscheid bijvoorbeeld: Kanselaar G, Jong T de, Andriessen J, Goodyear P. New technologies. In: Simons RJ, Linden J van der, Duffy T, editors. New Learning. Dordrecht/Boston/London: Kluwer Academic Publishers; 2000. p. 58.
} 
student zich focussen op leerstrategische uitkomsten. Daarbij gaat het niet alleen om de vraag of het gestelde prestatiedoel behaald is, maar ook of er vooruitgang in het leerproces is.

In de uitvoeringsfase staan de processen die inspanning en motivatie bij de uitvoering van het leerproces beïnvloeden centraal: aandacht richten, zelfinstructie en zelfmonitoring. Bij aandacht richten gaat het erom dat de student zichzelf kan 'beschermen' tegen afleiding door concurrerende activiteiten. Bij de zelfinstructie gaat het er om of de student de adequate studiestrategie kan inzetten op het juiste moment, bijvoorbeeld door het maken van uittreksels. Door zelfmonitoring kan de student sterke en zwakke kanten in het eigen leerproces signaleren en bijsturen. ${ }^{9}$

In de fase van de zelfreflectie gaat het om de activiteiten waarmee de opgedane leerervaring kan worden verwerkt. Door zelfevaluatie vergelijkt de student de opgedane ervaring en kennis met een bepaalde standaard. Zelfevaluatie leidt tot opvattingen over de oorzaken van het al dan niet halen van het doel: attributies. Studenten met een sterk zelfregulerend vermogen schrijven fouten vaker toe aan corrigeerbare oorzaken en succes aan persoonlijk vermogen. Attributies leiden tot positieve of negatieve zelfreacties (self reactions), het waardeoordeel dat een student zichzelf toekent ten gevolge van de attributie van het slagen of falen. Het proces waarin de student in staat is de opgedane inzichten te adapteren en in een nieuw leerproces om te zetten, is een activiteit die de brug slaat naar de planningsfase; daarmee is de cyclus rond. 8

\section{Doelen stellen}

Het stellen van doelen wordt een centraal uitgangspunt van zelfregulatie genoemd. Doelen beïnvloeden gedrag van personen op vier manieren. Doelen sturen de aandacht, hebben een stimulerende functie en beïnvloeden de mate waarin personen volharden in de taakuitvoering. Op indirecte wijze beïnvloeden doelen verder het gedrag door stimulering van het zoeken en gebruiken van relevante kennis en strategieën om het doel te bereiken. ${ }^{1}$

De keuze van het leerdoel beïnvloedt het totale proces van zelfregulatie. Doelen stellen vormt de kern van de planningsfase, in de uitvoeringsfase zijn de activiteiten gericht op het realiseren van deze doelen, en in de evaluatiefase op het evalueren en bijstellen ervan.

Wanneer de student zichzelf een duidelijk doel gesteld heeft, is een keuze gemaakt voor de inhoud van het leerproces; het gewenste resultaat is vastgelegd en daarmee is de richting van het leerproces bepaald ('Wat wil ik leren?'). Afhankelijk van het gekozen leerdoel bepaalt de student vervolgens hoe het leerdoel wordt gerealiseerd ('Hoe wil ik dat leren?'). Bij beide keuzes speelt de motivatie van de student een rol ('Waarom wil ik dat leren?').

Een duidelijk gesteld doel is dus een noodzakelijke voorwaarde voor zelfregulatie van het leerproces. Verondersteld wordt dat een student die het leerproces stuurt, de ruimte gebruikt die het constructivistisch onderwijs biedt. Deze student participeert actief in het onderwijs om de kennis te construeren die nodig is om het persoonlijke leerdoel te realiseren. 10

\section{Het gespreksvaardigheidsonderwijs}

Als voorbereiding op de co-schappen in het derde jaar krijgen de studenten in het eerste en tweede jaar onder meer gespreksvaardigheidsonderwijs. Dit is gebaseerd op verschillende constructivistische uitgangspunten. ${ }^{11}$

Het onderwijs wordt in werkgroepvorm onder leiding van een werkgroepbegelei- 
der gedurende tien dagdelen van drie uur aan twaalf tot veertien studenten gegeven. De structuur en werkvormen zijn voor beide leerjaren nagenoeg hetzelfde. Een dagdeel omvat naast een theoretisch gedeelte ook een praktisch gedeelte waarin twee studenten plenair gesprekken met een simulatiepatiënt voeren. Medestudenten observeren deze gesprekken en na afloop wordt dit nabesproken onder leiding van de werkgroepbegeleider. Naast de gesprekken met de simulatiepatiënt in de werkgroep, voeren de studenten in de onderwijsperiode ook tweemaal een gesprek met een simulatiepatiënt in een spreekkamer. Bij dit gesprek is één medestudent als observator aanwezig. Dit spreekkamergesprek wordt op videoband opgenomen, zodat het gesprek achteraf geanalyseerd kan worden. Studenten moeten naar aanleiding van hun gesprekken en video-opnamen leerpunten formuleren waaraan ze gedurende de cursus werken. Aan het eind van het eerste en tweede jaar wordt een stationstoets afgenomen. ${ }^{12}$ In één van de stations worden de gespreksvaardigheden getoetst.

\section{Probleemstelling}

Werkgroepbegeleiders van het gespreksvaardigheidsonderwijs hebben de indruk dat studenten de gespreksvaardigheden ongericht leren en moeite hebben met het sturen van hun leerproces. Wij vroegen ons af of dit deels wordt veroorzaakt door het feit dat studenten moeite hebben met het formuleren van leerdoelen. De doelstelling van deze exploratieve studie is inzicht te krijgen in de wijze waarop tweedejaars geneeskundestudenten leerdoelen formuleren. Daartoe worden vier deelvragen beantwoord:

1. Kan de werkgroepbegeleider het bijsturen van leerdoelen beïnvloeden?

2. Op welke onderwerpen hebben leerdoelen van studenten betrekking?
3. Zijn leerdoelen te realiseren binnen het gespreksvaardigheidsonderwijs in het tweede jaar?

4. Worden items waarop studenten tijdens de gespreksvaardigheidstoets van jaar 1 onvoldoendes haalden, verwerkt in het leerdoel?

\section{Methode}

\section{Procedure}

Aan een groep tweedejaars geneeskundestudenten (vijf mannen en zeven vrouwen) is tijdens het gespreksvaardigheidsonderwijs 2002-2003 onder leiding van een werkgroepbegeleider (MvdR) gevraagd zelfbeoordelingsvragenlijsten in te vullen. $\mathrm{Na}$ afloop van de eerste onderwijsbijeenkomst, waarin het overzicht van de leerstof voor het tweede jaar is gepresenteerd, werd de studenten gevraagd op basis van hun leerervaring en de gespreksvaardigheidstoets in het voorgaande jaar twee leerdoelen te formuleren ('Welke punten ga je aanpakken?') en deze naar de werkgroepbegeleider te mailen, zodat schriftelijk feedback op de leerdoelen gegeven kon worden. De studenten kregen daarna de gelegenheid de leerdoelen en leerstappen aan te passen. De op deze wijze ontstane leerdoelen zijn in deze studie gebruikt.

Met behulp van informatie uit de zelfbeoordelingsvragenlijst, de vaardigheidstoets en de emails van de werkgroepbegeleider worden de deelvragen beantwoord.

\section{Zelfbeoordelingsvragenlijst}

Als hulpmiddel voor de sturing van het leerproces wordt in het gespreksvaardigheidsonderwijs een zelfbeoordelingsvragenlijst gebruikt: open vragen die bedoeld zijn om de student aan te zetten tot het analyseren, plannen, uitvoeren en evalueren van het eigen leerproces. Deze vragenlijst sluit aan bij de plannings-, uitvoerings- en zelfreflectiefase van het 
zelfregulatiemodel van Zimmerman. ${ }^{8}$ De student wordt tijdens de eerste cursusbijeenkomst ondermeer gevraagd om (a) een moeilijke situatie uit het eerste jaar te beschrijven, (b) daaruit een leerdoel af te leiden, en (c) te motiveren waarom dat doel belangrijk is. De resultaten van vraag b zijn gebruikt om deelvraag 2 en 3 te beantwoorden.

\section{Eerstejaars gespreksvaardigheidstoets}

Aan het eind van het eerste jaar leggen studenten een stationsexamen af. In één station worden de gespreksvaardigheden getoetst. De student neemt gedurende vijftien minuten een anamnese af bij een simulatiepatiënt. Een beoordelaar observeert en beoordeelt de student aan de hand van acht items. Deze items hebben betrekking op het hanteren van het consultvoeringsmodel, het gebruiken van adequate gesprekstechnieken, de bejegening van de patiënt en de omgang met de emoties tijdens het gesprek. De scoring door de beoordelaar gebeurt op een vijfpuntsschaal ( $1=$ ernstige fout/kunstfout, $5=$ goed). De interne consistentie van deze items is vrij goed (Cronbach's alpha $\geq .71) .{ }^{13} \mathrm{Om}$ de vierde deelvraag te beantwoorden, zijn per student de resultaten van de gespreksvaardigheidstoets uit het eerste jaar opgevraagd.

\section{Schriftelijke feedback van de werkgroep- begeleider}

De emails met feedback van de werkgroepbegeleider zijn verzameld om na te gaan welke bijsturing nodig was om tot de formulering van leerdoelen te komen.

\section{Data-analyse}

Alle leerdoelen van de studenten zijn eerst geïnventariseerd en gegroepeerd op inhoudelijk onderwerp van het leerdoel. Daarna zijn de leerdoelen beoordeeld op realiseerbaarheid. Een doel wordt als te realiseren aangemerkt wanneer de inhoud van het doel de lesstof van het eerste jaar behelst of is ingebed in de lesstof van het tweede jaar. De domeinen, zoals genoemd op het beoordelingsformulier van de gespreksvaardigheidstoets, worden als beoordelingscriteria gebruikt. Twee beoordelaars (FG en MvdR) hebben onafhankelijk de leerdoelen gecategoriseerd en op realiseerbaarheid beoordeeld. Daarna is over verschillend beoordeelde items overlegd tot consensus werd bereikt.

Door de onderwerpen te inventariseren waarop de werkgroepbegeleider schriftelijke feedback heeft gegeven ten aanzien van de leerdoelen, is bepaald waar aandachtspunten bij het formuleren van leerdoelen liggen.

Per student is nagegaan op welke items van de gespreksvaardigheidstoets een onvoldoende is gehaald. Vervolgens is nagegaan of de items met een onvoldoende verwerkt zijn in de leerdoelen.

\section{Resultaten}

\section{Feedback van de werkgroepbegeleider}

Per student is eenmaal schriftelijk gereageerd per email. De inhoud van deze schriftelijke reacties ten aanzien van de leerdoelen zijn overwegend positief geformuleerd: "Ik vind je doel heel nuttig. Ook goed dat je je ervan bewust bent dat dit bij je zo werkt. Dan is het namelijk voor jezelf al een stuk makkelijker om je gedrag aan te pakken [...]." (nr. 1Bv).

De feedback is in géén van de gevallen gericht op het onderwerp van het leerdoel, maar vooral op de wijze waarop het leerdoel is omschreven. Studenten willen bijvoorbeeld gelijktijdig meerdere (diverse) doelen bereiken: "M., je wilt heel veel: doorvragen en markeren. Deze twee doelstellingen zijn zeker haalbaar maar dan moet je jezelf echt gerichte opdrachten geven. Die gerichte opdrachten zorgen 
ervoor dat je je er zelf beter en sneller van bewust bent [...]." (nr. 2Gv).

Uit de beschrijvingen bleek soms dat het voor de student zelf niet helder was wat zijn/haar probleem was. Dat resulteerde dan in een onduidelijk geformuleerd doel: "Je hebt goede punten. Ik vind het eerste punt getuigen van een kritische houding ten opzichte van jezelf. Dat vind ik sterk. Ik ga je twee vragen meegeven die je voor jezelf moet beantwoorden: [...] als je deze vragen hebt beantwoord moet daaruit naar voren komen wat je concreet zou moeten veranderen." (nr. $4 \mathrm{Mm})$.

Het accent in de feedback ligt niet zozeer op de leerdoelen zelf, maar op voornemens van studenten hoe ze dachten hun leerdoel te realiseren. Oorspronkelijk hadden de studenten in totaal 27 leerdoelen geformuleerd. Nadat de leerdoelen zijn bijgesteld op grond van de feedback, is het aantal gereduceerd tot 24 .

\section{Onderwerpen}

De 24 leerdoelen zijn in vijf verschillende onderwerpscategorieën onder te verdelen. In de categorie 'overig' zijn de leerdoelen ondergebracht die niet in andere categorieën zijn onder te brengen (tabel 1).

\section{Realiseerbaarheid}

22 leerdoelen zijn bij de toetsdomeinen van de vaardigheidstoets jaar 1 onder te brengen. De leerdoelen die betrekking hebben op 'angst om met boze en agressieve mensen om te gaan vanuit ervaringen in het verleden' en 'een goed gesprek voeren' kunnen niet worden ondergebracht bij een specifiek domein en worden in het kader van het gespreksvaardigheidsonderwijs als niet realiseerbaar geclassificeerd (tabel 1).

Tabel 1. Het aantal onvoldoendes in het station gespreksvaardigheden van de vaardigheidstoets jaar 1 van twaalf studenten, en hun geformuleerde en als realiseerbaar beoordeelde leerdoelen, gecategoriseerd naar onderwerp.

\begin{tabular}{|c|c|c|c|c|}
\hline Onderwerp & $\begin{array}{l}\text { Onvoldoende } \\
\text { toets ( } n=\text { item) }\end{array}$ & $\begin{array}{l}\text { Geformuleerd } \\
\text { ( } \mathrm{n}=\text { doel })\end{array}$ & $\begin{array}{l}\text { Realiseerbaar } \\
(\mathrm{n}=\text { doel })\end{array}$ & Voorbeeld van leerdoel \\
\hline (Door)vragen & 4 & 7 & 7 & $\begin{array}{l}\text { "Referentiekader op een natuurlijke } \\
\text { wijze uitvragen." (nr. 7-10Vv). }\end{array}$ \\
\hline $\begin{array}{l}\text { Emoties hanteren: } \\
\text { van zichzelf en de } \\
\text { patiënt }\end{array}$ & 2 & 6 & 5 & $\begin{array}{l}\text { "Vanwege mijn ervaring in het } \\
\text { dagelijks leven, ben ik bang dat ik } \\
\text { het moeilijk vind om met boze/ } \\
\text { agressieve mensen om te gaan. } \\
\text { Dit gegeven bekijken. Kijken of } \\
\text { het inderdaad zo is en zo ja, actie } \\
\text { ondernemen." (nr. 13-7Rv). }\end{array}$ \\
\hline $\begin{array}{l}\text { Structuren - } \\
\text { overzicht hebben }\end{array}$ & 1 & 5 & 5 & $\begin{array}{l}\text { "Structuur geven aan het gesprek; } \\
\text { met name de samenvatting." } \\
\text { (nr. 14-5Mm). }\end{array}$ \\
\hline Gesprekstempo & - & 3 & 3 & $\begin{array}{l}\text { "Mensen de ruimte geven om uit te } \\
\text { spreken." (nr. 20-8Sv). }\end{array}$ \\
\hline Overig & - & 3 & 2 & $\begin{array}{l}\text { "Eerder opvangen van de signalen } \\
\text { die de patiënt uitzendt over welke } \\
\text { kant het gesprek moet opgaan." } \\
(\mathrm{nr} \text {. 24-6Om). }\end{array}$ \\
\hline Totaal & 7 & 24 & 22 & \\
\hline
\end{tabular}




\section{Eerstejaars gespreksvaardigheidstoets}

Vijf studenten hebben in totaal zeven onvoldoendes op het gespreksvaardigheidsstation in de toets gescoord (tabel 1). De onvoldoendes zijn verdeeld over de items met betrekking tot emoties hanteren, structuur aanbrengen, doorvragen en het formuleren van vragen. In zes gevallen is het item dat onvoldoende is gescoord, verwerkt als leerdoel voor het gespreksvaardigheidsonderwijs van jaar 2. De student met een onvoldoende op het item structuur aanbrengen heeft dit niet als leerdoel voor het tweede jaar genomen.

\section{Discussie}

Onderwijs dat veelal op constructivistische uitgangspunten is gebaseerd, vraagt om studenten die hun leerproces zelf reguleren. Het stellen van doelen is een middel om het leerproces te sturen. In het gespreksvaardigheidsonderwijs hebben werkgroepbegeleiders het idee dat studenten ongericht leren en moeite hebben met het sturen van hun leerproces. Komt dat omdat studenten moeite hebben met het formuleren van leerdoelen? Nagegaan is hoe tweedejaars geneeskundestudenten doelen formuleren in het gespreksvaardigheidsonderwijs.

Studenten formuleren leerdoelen die wat betreft inhoud passen binnen het gespreksvaardigheidsonderwijs; de onderwerpen sluiten aan bij het onderwijs van het eerste en tweede jaar. De doelen lijken dus realiseerbaar. De items waarop een onvoldoende werd gescoord tijdens de gespreksvaardigheidstoets komen meestal als leerdoel terug. Beperkte bijsturing door de werkgroepbegeleider leidt tot reductie van het aantal (onduidelijk omschreven) doelen. Gesteld dat deze groep studenten inderdaad moeite heeft met de sturing van hun leerproces, dan lijkt doelen formuleren daarvan niet een aanwijsbare oorzaak.
Ons onderzoek heeft enkele belangrijke methodologische beperkingen.

1. Ten aanzien van het invullen van de zelfbeoordelingsvragenlijst speelt mee dat er geen gegevens bekend zijn over de betrouwbaarheid en de validiteit van deze lijst. Daarnaast was het invullen van de zelfbeoordelingsvragenlijst een voorwaarde om aan de toets mee te kunnen doen. Er is dus sprake van een externe prikkel. Dit kan sociaal wenselijk gedrag in de hand hebben gewerkt ten aanzien van de leerdoelformulering.

2. Het betreft een pilotstudy bij een klein aantal studenten van één groep. Er kan sprake zijn van een groepseffect, bijvoorbeeld doordat deze groep een hoger niveau heeft in vergelijking tot de rest van de studenten.

3. De studenten zijn door één werkgroepbegeleider begeleid. De uitkomsten kunnen een weergave zijn van datgene wat de werkgroepbegeleider zélf belangrijk vond. Ook kunnen er allerlei interactie-effecten zijn opgetreden tussen de werkgroepbegeleider en de groep.

4. De werkgroepbegeleider heeft tussentijds feedback gegeven. In dit onderzoek is niet nagegaan wat de kwaliteit van de schriftelijke feedback is. Informatie over mondelinge bijsturing tijdens de lessen is niet te achterhalen. Dit kan een vertekening van de resultaten veroorzaken. Voorzichtigheid moet worden betracht bij de generalisatie van de bevindingen van deze pilotstudy naar de gehele populatie tweedejaarsstudenten.

Er zijn aanwijzingen dat deze groep studenten in staat is om zelf kennis te construeren zoals dat binnen het constructivistisch onderwijs wordt aangemoedigd. Ten eerste blijkt dat de studenten na geringe bijsturing 
leerdoelen formuleren die grotendeels te realiseren zijn binnen het onderwijs. Ten tweede lijken de leerdoelen niet 'zomaar' gekozen. Dat blijkt niet alleen uit de persoonlijke onderbouwing die de studenten geven; de gekozen leerdoelen lijken vooral de 'moeilijke onderwerpen' uit het gespreksvaardigheidsonderwijs te betreffen. Het zijn onderwerpen waarop de studenten relatief veel onvoldoendes halen. ${ }^{13}$ Ten slotte blijken de studenten de items waarop zij tijdens de gespreksvaardigheidstoets een onvoldoende hebben gescoord, vaak in een leerdoel te verwerken. Kortom, studenten verwerken informatie die eerder in het leerproces is verkregen op actieve wijze.

Echter, de indruk van de werkgroepbegeleiders blijft dat studenten moeite hebben met sturing van hun leerproces. Uit de gegeven feedback van de werkgroepbegeleider blijkt dat bijsturing niet zozeer nodig is op de vraag 'Wat wil ik leren?' het leerdoel, maar vooral op de vraag 'Hoe wil ik dat leren?' - de concretisering van het leerdoel. In vervolgonderzoek wordt geëxploreerd welke strategieën en leerstappen studenten denken te gebruiken om hun zelfgestelde leerdoel binnen het gespreksvaardigheidsonderwijs te realiseren.

\section{Dankbetuiging}

De auteurs bedanken de groep tweedejaars studenten voor de bereidheid en de openheid waarmee zij hun leerproces hebben beschreven en prof. dr. Th. J. ten Cate voor het opbouwende commentaar op de eerdere versies van dit artikel.

\section{Literatuur}

1. Locke EA, Latham GP. Building a practically useful theory of goal setting and task motivation. A 35-year odyssey. Am Psychol 2002;57(9):705-17.

2. Kanselaar G, Jong T de, Andriessen J, Goodyear P. New technologies. In: Simons RJ, Linden J van der, Duffy T, editors. New Learning. Dordrecht/ Boston/London: Kluwer Academic Publishers; 2000. p. 55-82.
3. Schelfhout LW. Kritische beschouwingen bij het constructivisme. Tijdschrift voor Hoger Onderwijs 2002;2:94-124.

4. Windschitl M. Framing constructivism in practice as the negotiation of dilemmas: an analysis of the conceptual, pedagogical, cultural, and political challenges facing teachers. Review of Educational Research 2002;72(2):131-75.

5. Brown JS, Collins A, Duguid P. Situated cognition and the culture of learning. Educational Researcher Vol. 18, No.1. Washington: American Educational Research Association; 1989. p. 32-42.

6. Cognition and Technology Group at Vanderbilt. Anchored instructions and situated cognition revisited. Educational Technology 1993;33(3):5269.

7. Cate O ten, Snell L, Mann K, Vermunt J. Orienting teaching toward the learning process. Acad Med 2004;79(3):219-28.

8. Zimmerman BJ. Developing self-fulfilling cycles of academic regulation: an analysis of exemplary instructional models. In: Schunk DH, Zimmerman BJ, editors. Self-regulated learning. From teaching to self-reflective practice. New York/London: The Guilford Press; 1998. p. 1-19.

9. Carver C, Scheier M. Attention and self-regulation: A control theory approach to human behavior. New York: Springer-Verlag; 1981. p. 185-201.

10. Hout-Wolters B van, Simons RJ, Volet S. Active learning: self-directed learning and independent work. In: Simons RJ, Linden J van der, Duffy T, editors. New Learning. Dordrecht/Boston/London: Kluwer Academic Publishers; 2000. p. 2136.

11. Batenburg V. Nieuw curriculum geneeskunde Utrecht. Voorstel Praktisch Lijn Onderwijs: Communicatie en Attitude. Intern document versie: plo.com, 2 februari 1999.

12. Eijzenbach V, Batenburg V, Buis J, Grosfeld F, Kuyvenhoven M, Ridder M van de. Toetsing Praktisch Lijn Onderwijs Utrechts Curriculum (1). Consultexamen als toets voor klinische vaardigheden. In: Nederlandse Vereniging voor Medisch Onderwijs. Programma NVMO congres; 14-15 November 2002; Egmond aan Zee. Houten: Bohn Stafleu van Loghum; 2002. p. 32.

13. Grosfeld F, Batenburg V, Buis J, Eijzenbach V, Kuyvenhoven M, Ridder M van de. Toetsing Praktisch Lijn Onderwijs Utrechts Curriculum (2). Een empirisch onderzoek naar de validiteit van de communicatievaardigheidstoets voor jaar 1 en 2. In: Nederlandse Vereniging voor Medisch Onderwijs. Programma NVMO congres; 14-15 November 2002; Egmond aan Zee. Houten: Bohn Stafleu van Loghum; 2002. p. 33. 
De auteurs:

Mw. drs. J.M.M. van de Ridder, aio, is verbonden aan het Expertisecentrum voor Onderwijs en Opleiding, Directie Onderwijs en Opleidingen, UMC Utrecht.

Dr. F.J.M. Grosfeld, docent/onderzoeker, is verbonden aan de afdeling Klinisch Vaardigheids Onderwijs, Directie Onderwijs en Opleidingen, UMC Utrecht.
Correspondentieadres:

Mw. drs. J.M.M. van de Ridder, Expertisecentrum voor Onderwijs en Opleiding, Directie Onderwijs en Opleidingen, UMC Utrecht, Postbus 85500, 3508 GA Utrecht, tel.: 030-2503498, fax: 030-2538200, j.m.m.vanderidder @umcutrecht.nl.

\section{Summary}

Introduction: Goal setting is a first step in a learning process. Medical students must be aware of their own learning processes, since medical education is increasingly based on constructivist principles. Students appear to have difficulty in setting learning goals. We used Zimmerman's self regulation model to explore medical students' ability to set learning goals for a communication training course.

Method: Twelve second year undergraduate medical students were asked to set two goals to be achieved during a communication training course on the basis of previous experiences and training. They were stimulated to adjust these goals on the basis of written feedback from their teacher. These goals were collected, categorised and the feasibility of the goals was judged.

Results: The 24 goals that were collected appeared to be related to particularly complex tasks, some of which reflected poor marks on the communication exam of the previous year, i.e. asking about and dealing with patients' emotions. Twenty-two goals seemed feasible. The teacher commented on the number of implicit sub goals - often too many-and on the clarity of the goal descriptions.

Conclusion and discussion: Students seem to actively process the information they have acquired during previous learning experiences. Setting learning goals appeared to pose no problems and the goals required little modification. We conclude that students have little difficulty in setting learning goals for communications skills. (Van de Ridder JMM, Grosfeld FJM. Self regulation in setting learning goals for communication skills. Dutch Journal of Medical Education 2005;24(6):250-258.) 